\title{
Hatay'da Kullanılan Kuyu Sularının İçme Suyu Kalite Parametreleri Bakımından İncelenmesi ve Kemometrik Yöntemlerle Karakterizasyonu
}

\author{
Tuba TEKELII ${ }^{1 *}$, Yasin YÜCEL ${ }^{2}$, Yener TEKELİ ${ }^{3}$
}

\author{
${ }^{1}$ İskenderun Teknik Üniversitesi, İskenderun Meslek Yüksek Okulu, İskenderun Hatay \\ ${ }^{2}$ Mustafa Kemal Üniversitesi, Fen Edebiyat Fakültesi Kimya Bölümü, Antakya Hatay \\ ${ }^{3}$ Adıyaman Üniversitesi Eczacılık Fakültesi, Adıyaman
}

*Sorumlu Yazar: tuba.unes@iste.edu.tr

Geliş Tarihi: 17.06 .2018

Kabul Tarihi: 31.12 .2018

\section{Öz}

Yeraltı suları genellikle kuyu sularıdır. Yer üstü suları ise nehir, dere, çay, göl ve baraj sularıdır. Dünya su kaynaklarının yaklaşık \% 97,2 si tuzlu sudur. Türkiye su kaynakları bakımından önemli ülkelerden biridir. Ülkemizde 98 milyar $\mathrm{m}^{3}$ 'ü yerüstü ve 12 milyar $\mathrm{m}^{3}$ '̈̈ yeraltı suyu olmak üzere 110 milyar $\mathrm{m}^{3}$ 'lük toplam su kaynağ1 bulunmaktadır. Su ihtiyacının giderek arttığı ülkemizde yeraltı suyunun kirliliğinin kontrolü ve önlenmesi çalışmaları önem kazanmaktadır. Bu çalışmada, Antakya bölgesinde içme ve kullanma suyu olarak tüketilen kuyu sularından örnekler alınarak İnsani Tüketim Amaçlı Sular Hakkındaki Yönetmelikte belirtilen içme suyu kalite parametreleri bakımından analiz edilmiştir. Elde edilen sonuçların Türk Standartlar Enstitüsü (TS 266) ve Dünya Sağlık Örgütü (WHO) tarafından belirlenen içme suyu kalite standartları kriterlerine uygunluğu araştırılmıştır. Bölgedeki çevresel kirliliğin Antakya bölgesinde kullanılan kuyu sularına etkileri belirlenmiştir. Bunun yanında toplanan kuyu suyu örneklerinin ağır metal içeriğine bağlı olarak temel bileşen analizi ve öbekleme analizi gibi kemometrik tekniklerle kimyasal karakterizasyonu yapılmıştır.

Anahtar Kelimeler: Yeraltı suları, ağır metal analizi, öbekleme analizi, kemometrik metot.

\section{Investigation of Well Water Resources According To Their Quality Parameters Used in Hatay and Characterization by Chemometric Methods}

\begin{abstract}
Underground waters are usually well water. Also over ground waters are river, stream, lake and dam water. Approximately $97,2 \%$ of world water resources is saline water. Turkey is one of the important countries in terms of water resources. In our country, 98 billion $\mathrm{m}^{3}$ of over ground waters and 12 billion $\mathrm{m}^{3}$ of underground water surface, including water supply has a total of 110 billion $\mathrm{m}^{3}$. Increasing need for water pollution control and prevention of groundwater studies in our country is important. In this study, well waters which are consumed as drinking water in Antakya analyzed according to drinking water quality parameters specified in the Regulation on Water Intended for Human Consumption. Results investigated according to eligibility criteria for drinking water quality standards obtained by the Institute of Turkish Standards (TS 266) and the World Health Organization (WHO). The effect of environmental pollution in the region on the well waters used in the region of Antakya determined. Along with this, according to the heavy metal ingredience of the gathered well water samples, the chemical characterization was done by chemometric methods like principal component analysis and cluster analysis.
\end{abstract}

Keywords : Underground waters, heavy metal analysis, cluster analysis, chemometric method. 


\section{Giriş}

Yaşadığımız dünyada su hem doğal hayatın hem de insan hayatının varlığını sürdürebilmesi için gerekli olan temel ihtiyaçlardan biridir. Sınırlı doğal kaynaklar içinde yer alan su, bir ülkenin zenginliği, medeniyetlerin gelişmesi ve gelecek kuşaklara aktarılabilecek en değerli hazine durumundadır. Bir insanın sadece biyolojik ihtiyaçları için günde 2 litre suya ihtiyacı vardır. Temizlik, yemek, ısınma gibi günlük ihtiyaçlar ve giyinme barınma gibi endüstriyel ihtiyaçlarda düşünülürse günlük ihtiyacımız olan su miktarı daha da artar. Yeryüzündeki su kaynaklarının yaklaşık olarak \% 99,4 $\left(1,4.10^{9} \mathrm{~km}^{3}\right)$ 'lük bölümü yerüstü, \% 0,6'sı yeraltı suyudur. Dünya su kaynakları bakımından incelenirse, toplam su kaynaklarının yaklaşık \% 97,2'si tuzlu su olarak okyanuslarda bulunur. Karalar toplam suyun \% 2,8'ini, buzullar ise \% 2,1 ini bulundurmaktadır. 4000 metre derinliğe kadarki yer altı suları \% 0,61'i dir. Zemin nemi \% 0,0005; göllerdeki tatlı su $\%$ 0,009; nehirler \% 0,0001 ve tuzlu göller ise \% 0,008'idir. Toprak alanların suyunun \% 75'inden fazlası tuzlu sudur veya buzullarda saklıdır. Tatlı su olarak insanların kullanabileceği sular dünyanın su kapasitesinin sadece küçük bir yüzdesidir. Dünya da içme-kullanma, sulama ve endüstriyel amaçlarla gereksinim duyulan suyun, \% 0,3'ü göller ve \% 0,003'ü akarsularda olmak üzere, çok az bir bölümü yerüstü su kaynaklarında bulunmaktadır. Buna karşılık, \% $22\left(9.10^{6} \mathrm{~km}^{3}\right)$ gibi çok önemli bir oranla yeraltı suyu olarak tüketilebilecek durumdadır (Fetter,1994; Bear ve Cheng, 1999). Yeraltı suyunun ülkemizde ve dünyada artan su ihtiyacının karşılanmasında, giderek daha fazla kullanılması nedeniyle potansiyel bir kirlenme durumu söz konusudur. Kirletilen su kaynağının temizlenmesinin, korunmasından daha güç ve pahalı olduğu bilinen bir gerçektir. Bu nedenle, yeraltı suyunun kirliliğinin kontrolü ve önlenmesi çalışmalarının yapılması gerekmektedir (Tombul ve Bilgin, 1998). Günümüz teknolojik ve ekonomik koşulları çerçevesinde çeşitli amaçlara yönelik tüketilebilecek yüzey suyu potansiyeli, ülke içindeki akarsulardan 95 milyar $\mathrm{m}^{3}$ su ve komşu ülkelerden ülkemize gelen 3 milyar $\mathrm{m}^{3}$ suyla toplam 98 milyar $\mathrm{m}^{3}$ 'ü bulmaktadır. Yapılan teknik hesaplara göre, çeşitli şekillerde yerüstüne çıkarılabilen su miktarı 14 milyar $\mathrm{m}^{3}$ civarındadır. Çalışmalar ve etütler, günümüz şartlarında yurdumuzun tüketilebilir yüzey ve yeraltı suyu potansiyelinin yılda ortalama 112 milyar $\mathrm{m}^{3}$ olduğunu göstermektedir (Burak ve ark., 1997:6). Bugünkü koşullarda 95 milyar $\mathrm{m}^{3}$ yüzey suyu potansiyelimizin ancak 27,5 milyar $\mathrm{m}^{3}$ 'ünden (\%29) yararlanılabilmektedir. Yararlanılan su potansiyelinin 20,9 milyar $\mathrm{m}^{3}{ }^{\prime} \ddot{\mathrm{u}}(\% 76)$ sulamada, 3,85 milyar $\mathrm{m}^{3}$ 'ü (\%14) belediyeler tarafindan içme suyu olarak, 2,75 milyar $\mathrm{m}^{3}$ 'ü (\%10) de sanayide kullanılmaktadır (Burak ve ark., 1997:1).

Bu çalışmada Antakya bölgesinde içme ve kullanma suyu olarak tüketilen kuyu sularından örnekler alınarak İnsani Tüketim Amaçlı Sular Hakkındaki Yönetmelikte belirtilen içme suyu kalite parametreleri bakımından analiz edilmiştir. Elde edilen sonuçların Türk Standartlar Enstitüsü (TS 
266), Dünya Sağlık Örgütü (WHO), ABD ve Hollanda İçme Suyu Standartları tarafından belirlenen içme suyu kalite standartları kriterlerine uygunluğu araştırılmış, bölgedeki çevresel kirliliğin Antakya bölgesinde kullanılan kuyu sularına etkileri belirlenmiştir. Daha sonra Hatay Antakya'da içme ve kullanma suyu olarak tüketilen kuyu sularının kemometrik teknikler kullanılarak karakterize edilmiş ve kaynak orijinlerinin belirlenmiştir.

\section{Materyal ve Metot}

\subsection{Su Örneklerinin Toplanması}

Su örnekleri 2012 yılının Mayıs ayından, 2012 yılının Haziran ayının sonuna kadar Antakya ve İskenderun ilçesindeki kuyu sularından temin edilmiştir. Toplanan su numunelerinin alındığ yerler Şekil 2.1 ve Tablo 2.1'de belirtilmiştir. Arazide analiz edilmesi gereken parametreler analiz edilerek kayıt altına alınmıştır. Polietilen olan numune kaplarının üzerine suyun alındığı yerleşim yerinin adresi kaydedilip numara verilerek analiz edilmek üzere laboratuvara getirilmiştir. Araştırmada toplanan su örnekleri $+4^{\circ} \mathrm{C}$ 'de muhafaza edilerek laboratuvara getirildikten hemen sonra analizlere başlanmıştır.

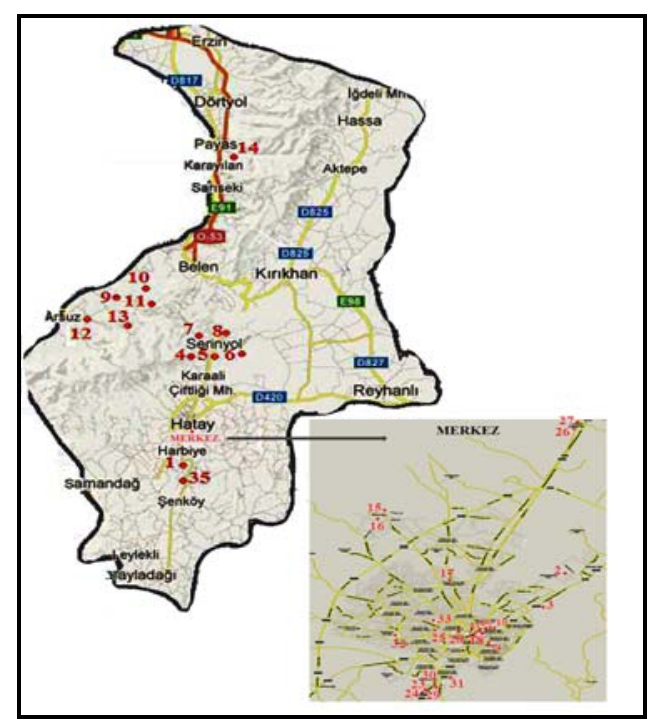

Şekil 2.1. Hatay merkez ve genelinde numune toplanan noktalar. 
Tablo 2.1. Numunelerin alındığı bölgeler.

\begin{tabular}{|c|c|c|c|c|c|}
\hline $\begin{array}{c}\text { Numune } \\
\text { no }\end{array}$ & $\begin{array}{l}\text { Numunenin Alındığı } \\
\text { Yer }\end{array}$ & $\begin{array}{l}\text { Numunenin } \\
\text { Alındığı Tarih }\end{array}$ & $\underset{\text { no }}{\text { Numune }}$ & $\begin{array}{l}\text { Numunenin } \\
\text { Alındığı Yer }\end{array}$ & $\begin{array}{l}\text { Numunenin } \\
\text { Alındığı Tarih }\end{array}$ \\
\hline 1 & ANTAKYA-Harbiye & Mayıs 2012 & 18 & $\begin{array}{l}\text { ANTAKYA- } \\
\text { Merkez }\end{array}$ & May1s 2012 \\
\hline 2 & ANTAKYA-Merkez & Mayıs 2012 & 19 & $\begin{array}{l}\text { ANTAKYA- } \\
\text { Merkez }\end{array}$ & May1s 2012 \\
\hline 3 & ANTAKYA-Merkez & Mayıs 2012 & 20 & $\begin{array}{l}\text { ANTAKYA- } \\
\text { Merkez }\end{array}$ & May1s 2012 \\
\hline 4 & ANTAKYA-Serinyol & Mayıs 2012 & 21 & $\begin{array}{l}\text { ANTAKYA- } \\
\text { Merkez }\end{array}$ & Haziran 2012 \\
\hline 5 & ANTAKYA-Serinyol & Mayıs 2012 & 23 & $\begin{array}{l}\text { ANTAKYA- } \\
\text { Merkez }\end{array}$ & Haziran 2012 \\
\hline 6 & ANTAKYA-Serinyol & Mayıs 2012 & 24 & $\begin{array}{l}\text { ANTAKYA- } \\
\text { Merkez }\end{array}$ & Haziran 2012 \\
\hline 7 & ANTAKYA-Serinyol & Mayıs 2012 & 25 & $\begin{array}{l}\text { ANTAKYA- } \\
\text { Merkez }\end{array}$ & Haziran 2012 \\
\hline 8 & ANTAKYA-Serinyol & Mayıs 2012 & 26 & $\begin{array}{l}\text { ANTAKYA- } \\
\text { Karaali Beldesi }\end{array}$ & Haziran 2012 \\
\hline 9 & HATAY -İskenderun & Mayıs 2012 & 27 & $\begin{array}{l}\text { ANTAKYA- } \\
\text { Karaali Beldesi }\end{array}$ & Haziran 2012 \\
\hline 10 & HATAY -İskenderun & Mayıs 2012 & 28 & $\begin{array}{l}\text { ANTAKYA- } \\
\text { Merkez }\end{array}$ & Haziran 2012 \\
\hline 11 & HATAY -İskenderun & Mayıs 2012 & 29 & $\begin{array}{l}\text { ANTAKYA- } \\
\text { Merkez }\end{array}$ & Haziran 2012 \\
\hline 12 & HATAY -İskenderun & Mayıs 2012 & 30 & $\begin{array}{l}\text { ANTAKYA- } \\
\text { Merkez }\end{array}$ & Haziran 2012 \\
\hline 13 & HATAY -İskenderun & Mayis 2012 & 31 & $\begin{array}{l}\text { ANTAKYA- } \\
\text { Merkez }\end{array}$ & Haziran 2012 \\
\hline 14 & HATAY -İskenderun & Mayıs 2012 & 32 & $\begin{array}{l}\text { ANTAKYA- } \\
\text { Merkez }\end{array}$ & Haziran 2012 \\
\hline 15 & $\begin{array}{l}\text { HATAY -İskenderun } \\
\text { Karayılan Beldesi }\end{array}$ & Mayıs 2012 & 33 & $\begin{array}{l}\text { ANTAKYA- } \\
\text { Merkez }\end{array}$ & Haziran 2012 \\
\hline 16 & $\begin{array}{c}\text { ANTAKYA-Ekinci } \\
\text { Beldesi }\end{array}$ & Mayıs 2012 & 34 & $\begin{array}{l}\text { ANTAKYA- } \\
\text { Merkez }\end{array}$ & Haziran 2012 \\
\hline 17 & ANTAKYA-Merkez & Mayıs 2012 & 35 & $\begin{array}{c}\text { ANTAKYA- } \\
\text { Merkez }\end{array}$ & Haziran 2012 \\
\hline
\end{tabular}




\subsection{Su Örneklerinin Sertlik ve Ağır Metal Analizi}

\subsubsection{Sertlik analizi}

Kalsiyum Sertliği: $100 \mathrm{~mL}$ su numunesi alınıp 2-4 ml $1 \mathrm{M} \mathrm{NaOH}$ çözeltisi ilave edilmiştir. $\mathrm{Mg}^{2+}$ iyonunu hidroksit halinde çöktürmek ve ortamın pH'sını 11 civarında tutmak için 0,1 g müreksid indikatörü (sadece $\mathrm{Ca}^{2+}$ iyonları ile renk verir) ilave edildikten sonra 0,01 M EDTA ile renk pembeden menekşeye dönene kadar titre edilmiştir.

Magnezyum Sertliği: Toplam sertlik için harcanan EDTA'nın hacminden Kalsiyum sertliği için harcanan EDTA'nın hacmi çıkartılıp EDTA'nın normalitesi ile çarpılmıştır.

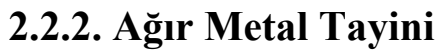

$\mathrm{Mn}, \mathrm{Ni}, \mathrm{Co}, \mathrm{Al}, \mathrm{Cd}, \mathrm{Cr}, \mathrm{Cu}, \mathrm{Fe}, \mathrm{Pb}$ ve $\mathrm{Zn}$ olmak üzere 10 element için yüksek saflıktaki standartlar ile farklı konsantrasyonlardaki stok çözeltileri hazırlanarak kalibrasyon eğrileri ICPOES'de okunmak suretiyle hazırlandı.

\subsubsection{Su Örneklerinin Kemometrik Analizleri}

Hatay merkezden toplanan 35 su örneği kemometrik metotlarla karakterize edilmiştir. Örneklerin eser element ve ağır metal içeriklerine göre karakterize edilmesinde temel bileşen analizi, öbekleme analizi ve korelasyon analizi kullanılmıştır. Temel bileşen analizi ve korelasyon analizi Excel programı ile yapılmıştır. Öbekleme analizinde ise Statistica 8.0 programı kullanılmıştır.

\section{Bulgular ve Tartışma}

Antakya ve İskenderun bölgesinden toplam 35 su numunesi toplanarak, 3 tekrarlı olmak üzere, fiziksel, kimyasal ve eser element analizleri yapılmıştır. Ayrıca yapılan temel bileşen ve öbekleme analizleri ile eser element içeriklerine göre su örnekleri karakterize edilmiştir. Bunun yanında çalışma sonucunda tespit edilen değerler, Türk Standartlar Enstitüsü (TS 266) ve Dünya Sağlık Örgütü (WHO) tarafından belirlenen içme suyu kalite standartları ile karşılaştırılmıştır.

Su numunelerinde $\mathrm{pH}$, toplam sertlik, kalsiyum sertliği ve magnezyum sertliği değerleri de Tablo 3.1.de verilmiştir. 
Tablo 3.1. su numunelerinin $\mathrm{pH}$ ve sertlik analiz sonuçları.

\begin{tabular}{|c|c|c|c|c|}
\hline $\begin{array}{c}\text { Örnek } \\
\text { No. }\end{array}$ & pH & $\begin{array}{c}\text { Toplam sertlik } \\
(\mathrm{mg} / \mathrm{L})\end{array}$ & $\begin{array}{c}\text { Kalsiyum sertliği } \\
(\mathrm{mg} / \mathrm{L})\end{array}$ & $\begin{array}{c}\text { Magnezyum sertliği } \\
(\mathrm{mg} / \mathrm{L})\end{array}$ \\
\hline 1 & $7,40 \pm 0,61$ & $184 \pm 2$ & $20 \pm 0,0$ & $164 \pm 0$ \\
\hline 2 & $7,33 \pm 0,26$ & $248 \pm 2$ & $11 \pm 0,0$ & $237 \pm 1$ \\
\hline 3 & $7,30 \pm 0,30$ & $224 \pm 2$ & $21 \pm 0,0$ & $203 \pm 1$ \\
\hline 4 & $7,98 \pm 0,26$ & $200 \pm 2$ & $4 \pm 0,0$ & $196 \pm 1$ \\
\hline 5 & $7,90 \pm 0,36$ & $232 \pm 2$ & $15 \pm 1,0$ & $217 \pm 1$ \\
\hline 6 & $7,90 \pm 0,26$ & $160 \pm 2$ & $6 \pm 1,0$ & $144 \pm 2$ \\
\hline 7 & $7,82 \pm 0,26$ & $212 \pm 3$ & $8 \pm 0,8$ & $204 \pm 2$ \\
\hline 8 & $7,70 \pm 0,62$ & $280 \pm 3$ & $8 \pm 1,0$ & $252 \pm 2$ \\
\hline 9 & $6,43 \pm 0,26$ & $316 \pm 2$ & $14 \pm 1,7$ & $302 \pm 2$ \\
\hline 10 & $6,43 \pm 0,30$ & $232 \pm 2$ & $13 \pm 1,0$ & $219 \pm 2$ \\
\hline 11 & $6,41 \pm 0,30$ & $312 \pm 2$ & $16 \pm 1,7$ & $296 \pm 2$ \\
\hline 12 & $6,39 \pm 0,26$ & $280 \pm 2$ & $7 \pm 1,0$ & $252 \pm 2$ \\
\hline 13 & $6,41 \pm 0,36$ & $212 \pm 2$ & $13 \pm 0,9$ & $199 \pm 0$ \\
\hline 14 & $6,65 \pm 0,30$ & $156 \pm 2$ & $21 \pm 0,9$ & $135 \pm 2$ \\
\hline 15 & $8,61 \pm 0,30$ & $204 \pm 2$ & $11 \pm 1,0$ & $193 \pm 2$ \\
\hline 16 & $7,09 \pm 0,30$ & $260 \pm 2$ & $12 \pm 1,7$ & $248 \pm 2$ \\
\hline 17 & $7,84 \pm 0,26$ & $256 \pm 2$ & $12 \pm 1,0$ & $244 \pm 3$ \\
\hline 18 & $7,53 \pm 0,30$ & $260 \pm 3$ & $37 \pm 1,0$ & $223 \pm 2$ \\
\hline 19 & $7,96 \pm 0,27$ & $256 \pm 2$ & $59 \pm 1,7$ & $197 \pm 2$ \\
\hline 20 & $7,44 \pm 0,30$ & $308 \pm 2$ & $97 \pm 1,0$ & $211 \pm 2$ \\
\hline 21 & $7,52 \pm 0,30$ & $300 \pm 2$ & $105 \pm 1,0$ & $195 \pm 2$ \\
\hline 22 & $7,42 \pm 0,30$ & $296 \pm 2$ & $95 \pm 1,0$ & $201 \pm 2$ \\
\hline 23 & $7,05 \pm 0,30$ & $392 \pm 2$ & $110 \pm 2,6$ & $282 \pm 2$ \\
\hline 24 & $7,23 \pm 0,70$ & $428 \pm 2$ & $313 \pm 1,0$ & $115 \pm 2$ \\
\hline 25 & $7,24 \pm 0,60$ & $245 \pm 2$ & $26 \pm 1,0$ & $219 \pm 2$ \\
\hline 26 & $6,85 \pm 0,30$ & $298 \pm 2$ & $31 \pm 1,0$ & $267 \pm 2$ \\
\hline 27 & $7,23 \pm 0,30$ & $280 \pm 4$ & $19 \pm 1,0$ & $261 \pm 2$ \\
\hline 28 & $6,96 \pm 0,52$ & $245 \pm 2$ & $24 \pm 1,0$ & $221 \pm 3$ \\
\hline 29 & $7,25 \pm 0,30$ & $316 \pm 4$ & $36 \pm 1,0$ & $280 \pm 2$ \\
\hline 30 & $7,16 \pm 0,30$ & $380 \pm 2$ & $59 \pm 1,0$ & $321 \pm 2$ \\
\hline 31 & $7,33 \pm 0,30$ & $240 \pm 3$ & $28 \pm 1,0$ & $212 \pm 2$ \\
\hline 32 & $7,41 \pm 0,27$ & $280 \pm 2$ & $29 \pm 1,0$ & $251 \pm 2$ \\
\hline 33 & $7,18 \pm 0,30$ & $320 \pm 2$ & $45 \pm 1,0$ & $275 \pm 2$ \\
\hline 34 & $7,26 \pm 0,36$ & $216 \pm 2$ & $37 \pm 1,0$ & $179 \pm 2$ \\
\hline 35 & $7,72 \pm 0,30$ & $272 \pm 3$ & $23 \pm 1,0$ & $249 \pm 2$ \\
\hline Ortalama & 7,30 & 266 & 39,6 & 224 \\
\hline Ortanca & 7,30 & 260 & 21,0 & 219 \\
\hline Std sapma & 0,52 & 60,3 & 55,7 & 46,8 \\
\hline Minimum & 6,39 & 156 & 4,0 & 115 \\
\hline Maksimum & 8,61 & 428 & 313,0 & 321 \\
\hline
\end{tabular}


Ağır metal analizi için metodun geçerliliği; sertifikalı referans malzeme (CRM) kullanılarak yapılan geri kazanım çalışması ile sağlanmıştır. Standart madde ile beraber su numuneleri aynı ölçüm dizini içinde ICP OES ile analiz edilmiştir. Kuyu suyu numunelerinin Mn, Ni, Co, Al, Cd, $\mathrm{Cr}, \mathrm{Cu}, \mathrm{Fe}, \mathrm{Pb}$ ve $\mathrm{Zn}$ elementlerinden oluşan ağır metal analiz sonuçları ise Tablo 3.2.. de tüm numunelerin ağır metal analiz sonuçlarının istatistiksel değerleri ise Tablo 3.3. de verilmiştir.

Tablo 3. 2. Kuyu suyu numunelerinin ağır metal analiz sonuçları, $(\mathrm{mg} / \mathrm{L}),(\mathrm{n}=3)$

\begin{tabular}{|c|c|c|c|c|c|c|c|c|c|c|}
\hline $\begin{array}{l}\text { Örn. } \\
\text { No. }\end{array}$ & Mn & $\mathbf{N i}$ & Co & Al & Cd & $\mathrm{Cr}$ & $\mathrm{Cu}$ & $\mathrm{Fe}$ & $\mathbf{P b}$ & Zn \\
\hline \multirow{2}{*}{1} & $0,0007 \pm 0$ & $0,0050 \pm 0$ & $0,0047 \pm 0$ & $0,0066 \pm 0$ & $0,0011 \pm 0$ & $0,0068 \pm 0$ & $0,0058 \pm 0$ & $0,0016 \pm 0$ & $0,0152 \pm 0$ & $0,0017 \pm 0$ \\
\hline &, 0001 &, 0006 & ,0006 &, 0014 &, 0002 &, 0005 &, 0007 &, 0002 &, 0024 &, 0004 \\
\hline \multirow{2}{*}{2} & $0,0005 \pm 0$ & $0,0058 \pm 0$ & $0,0040 \pm 0$ & $0,0080 \pm 0$ & $0,0009 \pm 0$ & $0,0183 \pm 0$ & $0,0058 \pm 0$ & $0,0016 \pm 0$ & $0,0185 \pm 0$ & $0,0015 \pm 0$ \\
\hline & ,0001 & ,0009 & ,0007 &, 0002 &, 0002 &, 000 & ,0004 & ,0001 &, 0013 &, 0001 \\
\hline \multirow{2}{*}{3} & $0,0009 \pm 0$ & $0,0113 \pm 0$ & $0,0046 \pm 0$ & $0,0060 \pm 0$ & $0,0011 \pm 0$ & $0,0048 \pm 0$ & $0,0071 \pm 0$ & $0,0016 \pm 0$ & $0,0162 \pm 0$ & $0,0176 \pm 0$ \\
\hline &, 0002 & ,0018 &, 0005 &, 0003 &, 0003 &, 000 & ,0014 &, 0003 & ,0018 &, 0036 \\
\hline \multirow{2}{*}{4} & $0,0007 \pm 0$ & $0,0067 \pm 0$ & $0,0046 \pm 0$ & $0,0071 \pm 0$ & $0,0013 \pm 0$ & $0,0215 \pm 0$ & $0,0053 \pm 0$ & $0,0013 \pm 0$ & $0,0133 \pm 0$ & $0,0049 \pm 0$ \\
\hline &, 0001 &, 0003 & ,0009 &, 0002 &, 0003 &, 000 &, 0013 &, 0005 &, 0067 &, 0015 \\
\hline \multirow{2}{*}{5} & $0,0006 \pm 0$ & $0,0054 \pm 0$ & $0,0055 \pm 0$ & $0,0054 \pm 0$ & $0,0009 \pm 0$ & $0,0312 \pm 0$ & $0,0050 \pm 0$ & $0,0012 \pm 0$ & $0,0129 \pm 0$ & $0,0033 \pm 0$ \\
\hline &, 0001 &, 0003 & ,0002 &, 0005 &, 0002 &, 000 & ,0008 & ,0002 & 0010 &, 0003 \\
\hline \multirow{2}{*}{6} & $0,0005 \pm 0$ & $0,0045 \pm 0$ & $0,0039 \pm 0$ & $0,0057 \pm 0$ & $0,0009 \pm 0$ & $0,0187 \pm 0$ & $0,0072 \pm 0$ & $0,0015 \pm 0$ & $0,0166 \pm 0$ & $0,0017 \pm 0$ \\
\hline & ,0001 &, 0010 &, 0004 &, 0014 &, 0001 &, 000 &, 0010 &, 0003 &, 0027 &, 0003 \\
\hline \multirow{2}{*}{7} & $0,0007 \pm 0$ & $0,0064 \pm 0$ & $0,0051 \pm 0$ & $0,0068 \pm 0$ & $0,0006 \pm 0$ & $0,0396 \pm 0$ & $0,0067 \pm 0$ & $0,0069 \pm 0$ & $0,0088 \pm 0$ & $0,0022 \pm 0$ \\
\hline & ,0001 &, 0002 & ,0004 & ,0004 &, 0001 &, 000 & ,0006 &, 0007 &, 0008 &, 0005 \\
\hline \multirow{2}{*}{8} & $0,0006 \pm 0$ & $0,0054 \pm 0$ & $0,0056 \pm 0$ & $0,0055 \pm 0$ & $0,0014 \pm 0$ & $0,0286 \pm 0$ & $0,0048 \pm 0$ & $0,0016 \pm 0$ & $0,0146 \pm 0$ & $0,0016 \pm 0$ \\
\hline & ,0001 & ,0008 &, 0013 &, 0011 &, 0002 &, 000 &, 0005 & ,0004 & ,0009 & ,0004 \\
\hline \multirow{2}{*}{9} & $0,0007 \pm 0$ & $0,0068 \pm 0$ & $0,0045 \pm 0$ & $0,0059 \pm 0$ & $0,0010 \pm 0$ & $0,0165 \pm 0$ & $0,0065 \pm 0$ & $0,0020 \pm 0$ & $0,0147 \pm 0$ & $0,0092 \pm 0$ \\
\hline &, 0001 &, 0006 & ,0004 & ,0011 &, 0003 &, 000 & ,0009 &, 0003 &, 0011 &, 0002 \\
\hline \multirow{2}{*}{10} & $0,0007 \pm 0$ & $0,0089 \pm 0$ & $0,0062 \pm 0$ & $0,0054 \pm 0$ & $0,0009 \pm 0$ & $0,0100 \pm 0$ & $0,0098 \pm 0$ & $0,0013 \pm 0$ & $0,0169 \pm 0$ & $0,0300 \pm 0$ \\
\hline & ,0001 &, 0015 & ,0002 &, 0003 &, 0001 &, 000 & ,0002 &, 0003 &, 0046 &, 0034 \\
\hline \multirow{2}{*}{11} & $0,0007 \pm 0$ & $0,0063 \pm 0$ & $0,0054 \pm 0$ & $0,0063 \pm 0$ & $0,0008 \pm 0$ & $0,0099 \pm 0$ & $0,0095 \pm 0$ & $0,0015 \pm 0$ & $0,0125 \pm 0$ & $0,0182 \pm 0$ \\
\hline & ,0001 & ,0007 &, 0005 &, 0011 & ,0002 &, 000 & ,0006 &, 0005 & ,0011 & ,0038 \\
\hline \multirow{2}{*}{12} & $0,0006 \pm 0$ & $0,0069 \pm 0$ & $0,0049 \pm 0$ & $0,0069 \pm 0$ & $0,0012 \pm 0$ & $0,0099 \pm 0$ & $0,0074 \pm 0$ & $0,0011 \pm 0$ & $0,0192 \pm 0$ & $0,0037 \pm 0$ \\
\hline & ,0001 &, 0013 & ,0006 &, 0010 & ,0002 &, 000 &, 0016 &, 0001 & ,0039 & ,0004 \\
\hline \multirow{2}{*}{13} & $0,0007 \pm 0$ & $0,0062 \pm 0$ & $0,0047 \pm 0$ & $0,0062 \pm 0$ & $0,0009 \pm 0$ & $0,0101 \pm 0$ & $0,0073 \pm 0$ & $0,0010 \pm 0$ & $0,0143 \pm 0$ & $0,0053 \pm 0$ \\
\hline & ,0002 &, 0004 &, 0015 &, 0010 & ,0001 &, 000 & ,0008 &, 0003 &, 0052 & ,0012 \\
\hline \multirow{2}{*}{14} & $0,0008 \pm 0$ & $0,0051 \pm 0$ & $0,0052 \pm 0$ & $0,0064 \pm 0$ & $0,0006 \pm 0$ & $0,0038 \pm 0$ & $0,0069 \pm 0$ & $0,0016 \pm 0$ & $0,0169 \pm 0$ & $0,0341 \pm 0$ \\
\hline & ,0001 &, 0010 &, 0005 & ,0006 &, 0002 &, 000 & ,0007 &, 0001 &, 0040 &, 0041 \\
\hline \multirow{2}{*}{15} & $0,0007 \pm 0$ & $0,0068 \pm 0$ & $0,0046 \pm 0$ & $0,0072 \pm 0$ & $0,0008 \pm 0$ & $0,0178 \pm 0$ & $0,0076 \pm 0$ & $0,0020 \pm 0$ & $0,0146 \pm 0$ & $0,0119 \pm 0$ \\
\hline &, 0001 &, 0020 &, 0011 & &, 0001 &, 000 &, 0004 & &, 0052 & \\
\hline \multirow{2}{*}{16} & $0,0007 \pm 0$ & $0,0063 \pm 0$ & $0,0056 \pm 0$ & $0,0047 \pm 0$ & $0,0012 \pm 0$ & $0,0094 \pm 0$ & $0,0077 \pm 0$ & $0,0013 \pm 0$ & $0,0113 \pm 0$ & $0,0004 \pm 0$ \\
\hline &, 0002 &, 0005 &, 0003 & ,0007 & ,0004 &, 000 &, 0010 & ,0004 &, 0025 &, 0001 \\
\hline \multirow{2}{*}{17} & $0,0008 \pm 0$ & $0,0059 \pm 0$ & $0,0060 \pm 0$ & $0,0052 \pm 0$ & $0,0013 \pm 0$ & $0,0161 \pm 0$ & $0,0063 \pm 0$ & $0,0022 \pm 0$ & $0,0155 \pm 0$ & $0,0073 \pm 0$ \\
\hline & ,0001 &, 0011 &, 0005 &, 0014 &, 0003 &, 000 &, 0014 &, 0004 & ,0049 &, 0006 \\
\hline \multirow{2}{*}{18} & $0,0584 \pm 0$ & $0,0071 \pm 0$ & $0,0053 \pm 0$ & $0,0066 \pm 0$ & $0,0010 \pm 0$ & $0,0004 \pm 0$ & $0,0055 \pm 0$ & $0,0015 \pm 0$ & $0,0069 \pm 0$ & $0,0024 \pm 0$ \\
\hline & ,0042 &, 0004 &, 0005 &, 0007 &, 0002 &, 000 & ,0004 & ,0004 & ,0019 & ,0003 \\
\hline \multirow{2}{*}{19} & $0,0037 \pm 0$ & $0,0097 \pm 0$ & $0,0050 \pm 0$ & $0,0071 \pm 0$ & $0,0010 \pm 0$ & $0,0189 \pm 0$ & $0,0071 \pm 0$ & $0,0015 \pm 0$ & $0,0125 \pm 0$ & $0,0117 \pm 0$ \\
\hline & &, 0007 & ,0007 & ,0001 &, 0002 &, 000 &, 0010 &, 0002 & & ,0019 \\
\hline \multirow{2}{*}{20} & $0,0012 \pm 0$ & $0,0083 \pm 0$ & $0,0059 \pm 0$ & $0,0069 \pm 0$ & $0,0011 \pm 0$ & $0,0145 \pm 0$ & $0,0088 \pm 0$ & $0,0016 \pm 0$ & $0,0173 \pm 0$ & $0,0044 \pm 0$ \\
\hline & ,0002 & ,0001 & ,0004 & ,0008 &, 0000 &, 000 & ,0012 & ,0004 &, 0056 & ,0018 \\
\hline & $0,0010 \pm 0$ & $0,0086 \pm 0$ & $0,0060 \pm 0$ & $0,0108 \pm 0$ & $0,0011 \pm 0$ & $0,0143 \pm 0$ & $0,0073 \pm 0$ & $0,0012 \pm 0$ & $0,0187 \pm 0$ & $0,0035 \pm 0$ \\
\hline 21 & &, 0010 & ,0009 &, 0010 &, 0003 &, 000 &, 0010 & ,0002 & ,0069 &, 0003 \\
\hline & $0,0008 \pm 0$ & $0,0059 \pm 0$ & $0,0047 \pm 0$ & $0,0041 \pm 0$ & $0,0008 \pm 0$ & $0,0018 \pm 0$ & $0,0072 \pm 0$ & $0,0016 \pm 0$ & $0,0159 \pm 0$ & $0,0098 \pm 0$ \\
\hline 22 &, 0002 &, 0034 &, 0003 &, 0005 &, 0004 &, 000 & ,0007 &, 0005 &, 0021 &, 0085 \\
\hline & $0,0011 \pm 0$ & $0,0106 \pm 0$ & $0,0043 \pm 0$ & $0,0088 \pm 0$ & $0,0012 \pm 0$ & $0,0009 \pm 0$ & $0,0092 \pm 0$ & $0,0014 \pm 0$ & $0,0122 \pm 0$ & $0,0051 \pm 0$ \\
\hline 23 & ,0002 &, 0023 &, 0005 & ,0016 & ,0002 &, 000 &, 0005 &, 0004 &, 0020 &, 0008 \\
\hline 24 & $0,0018 \pm 0$ & $0,0145 \pm 0$ & $0,0078 \pm 0$ & $0,0179 \pm 0$ & $0,0015 \pm 0$ & $0,0031 \pm 0$ & $0,0109 \pm 0$ & $0,0023 \pm 0$ & $0,0258 \pm 0$ & $0,0037 \pm 0$ \\
\hline
\end{tabular}




\begin{tabular}{cclllllllll} 
&, 0003 &, 0055 &, 0018 &, 0070 &, 0003 &, 000 &, 0037 &, 0003 &, 0030 &, 0029 \\
$\mathbf{2 5}$ & $0,0014 \pm 0$ & $0,0088 \pm 0$ & $0,0109 \pm 0$ & $0,0115 \pm 0$ & $0,0013 \pm 0$ & $0,0034 \pm 0$ & $0,0117 \pm 0$ & $0,0020 \pm 0$ & $0,0191 \pm 0$ & $0,0018 \pm 0$ \\
&, 0003 &, 0007 &, 0024 &, 0020 &, 0002 &, 000 &, 0017 &, 0007 &, 0036 &, 0003 \\
$\mathbf{2 6}$ & $0,0011 \pm 0$ & $0,0058 \pm 0$ & $0,0067 \pm 0$ & $0,0065 \pm 0$ & $0,0013 \pm 0$ & $0,0401 \pm 0$ & $0,0087 \pm 0$ & $0,0016 \pm 0$ & $0,0160 \pm 0$ & $0,0550 \pm 0$ \\
&, 0001 &, 0007 &, 0008 &, 0020 &, 0005 &, 000 &, 0004 &, 0003 &, 0025 &, 0122 \\
$\mathbf{2 7}$ & $0,0010 \pm 0$ & $0,0065 \pm 0$ & $0,0057 \pm 0$ & $0,0073 \pm 0$ & $0,0013 \pm 0$ & $0,0035 \pm 0$ & $0,0104 \pm 0$ & $0,0019 \pm 0$ & $0,0156 \pm 0$ & $0,0174 \pm 0$ \\
&, 0002 &, 0001 &, 0006 &, 0008 &, 0003 &, 000 &, 0012 &, 0004 &, 0028 &, 0129 \\
$\mathbf{2 8}$ & $0,0010 \pm 0$ & $0,0065 \pm 0$ & $0,0062 \pm 0$ & $0,0071 \pm 0$ & $0,0016 \pm 0$ & $0,0378 \pm 0$ & $0,0079 \pm 0$ & $0,0013 \pm 0$ & $0,0219 \pm 0$ & $0,0744 \pm 0$ \\
&, 0002 &, 0013 &, 0004 &, 0007 &, 0004 &, 000 &, 0003 &, 0001 &, 0035 &, 0130 \\
$\mathbf{2 9}$ & $0,0010 \pm 0$ & $0,0125 \pm 0$ & $0,0083 \pm 0$ & $0,0069 \pm 0$ & $0,0011 \pm 0$ & $0,0046 \pm 0$ & $0,0106 \pm 0$ & $0,0016 \pm 0$ & $0,0251 \pm 0$ & $0,0184 \pm 0$ \\
&, 0001 &, 0003 &, 0006 &, 0004 &, 0002 &, 000 &, 0017 &, 0006 &, 0045 &, 0084 \\
$\mathbf{3 0}$ & $0,0021 \pm 0$ & $0,0226 \pm 0$ & $0,0077 \pm 0$ & $0,0092 \pm 0$ & $0,0008 \pm 0$ & $0,0177 \pm 0$ & $0,0094 \pm 0$ & $0,0063 \pm 0$ & $0,0144 \pm 0$ & $0,0517 \pm 0$ \\
&, 0001 &, 0006 &, 0010 &, 0012 &, 0003 &, 000 &, 0004 &, 0008 &, 0017 &, 0013 \\
$\mathbf{3 1}$ & $0,0008 \pm 0$ & $0,0105 \pm 0$ & $0,0072 \pm 0$ & $0,0080 \pm 0$ & $0,0013 \pm 0$ & $0,0047 \pm 0$ & $0,0087 \pm 0$ & $0,0020 \pm 0$ & $0,0162 \pm 0$ & $0,0046 \pm 0$ \\
&, 0002 &, 0013 &, 0005 &, 0006 &, 0005 &, 000 &, 0017 &, 0005 &, 0070 &, 0009 \\
$\mathbf{3 2}$ & $0,0009 \pm 0$ & $0,0100 \pm 0$ & $0,0057 \pm 0$ & $0,0066 \pm 0$ & $0,0006 \pm 0$ & $0,0139 \pm 0$ & $0,0094 \pm 0$ & $0,0018 \pm 0$ & $0,0188 \pm 0$ & $0,0011 \pm 0$ \\
&, 0000 &, 0040 &, 0008 &, 0010 &, 0001 &, 000 &, 0012 &, 0001 &, 0036 &, 0002 \\
$\mathbf{3 3}$ & $0,0011 \pm 0$ & $0,0165 \pm 0$ & $0,0083 \pm 0$ & $0,0074 \pm 0$ & $0,0012 \pm 0$ & $0,0041 \pm 0$ & $0,0108 \pm 0$ & $0,0017 \pm 0$ & $0,0246 \pm 0$ & $0,0076 \pm 0$ \\
&, 0001 &, 0006 &, 0005 &, 0013 &, 0001 &, 000 &, 0013 &, 0001 &, 0038 &, 0004 \\
$\mathbf{3 4}$ & $0,0012 \pm 0$ & $0,0101 \pm 0$ & $0,0078 \pm 0$ & $0,0076 \pm 0$ & $0,0013 \pm 0$ & $0,0082 \pm 0$ & $0,0089 \pm 0$ & $0,0019 \pm 0$ & $0,0168 \pm 0$ & $0,0029 \pm 0$ \\
&, 0001 &, 0006 &, 0012 &, 0006 &, 0001 &, 000 &, 0028 &, 0002 &, 0028 &, 0002 \\
$\mathbf{3 5}$ & $0,0075 \pm 0$ & $0,0080 \pm 0$ & $0,0056 \pm 0$ & $0,0081 \pm 0$ & $0,0011 \pm 0$ & $0,0035 \pm 0$ & $0,0078 \pm 0$ & $0,0010 \pm 0$ & $0,0128 \pm 0$ & $0,0005 \pm 0$ \\
&, 0005 &, 0009 &, 0020 &, 0003 &, 0002 &, 000 &, 0001 &, 0002 &, 0006 &, 0001 \\
\hline
\end{tabular}

Tablo 3.3. Kuyu suyu numunelerinde ağır metal analiz sonuçlarının istatistiksel değerleri

\begin{tabular}{|c|c|c|c|c|c|c|c|c|c|c|}
\hline Örnekler & Mn & $\mathbf{N i}$ & Co & Al & Cd & $\mathrm{Cr}$ & $\mathrm{Cu}$ & $\mathrm{Fe}$ & $\mathbf{P b}$ & $\mathbf{Z n}$ \\
\hline Ortalama & 0,0028 & 0,0084 & 0,0058 & 0,0073 & 0,0011 & 0,0134 & 0,0079 & 0,0019 & 0,0161 & 0,0123 \\
\hline Ortanca & 0,0008 & 0,0068 & 0,0056 & 0,0069 & 0,0011 & 0,0100 & 0,0076 & 0,0016 & 0,0159 & 0,0049 \\
\hline Std. sapma & 0,0098 & 0,0037 & 0,0015 & 0,0024 & 0,0002 & 0,0110 & 0,0018 & 0,0012 & 0,0041 & 0,0172 \\
\hline Minimum & 0,0005 & 0,0045 & 0,0039 & 0,0041 & 0,0006 & 0,0004 & 0,0048 & 0,0010 & 0,0069 & 0,0004 \\
\hline Maksimum & 0,0584 & 0,0226 & 0,0109 & 0,0179 & 0,0016 & 0,0401 & 0,0117 & 0,0069 & 0,0258 & 0,0744 \\
\hline LOD & $\begin{array}{l}0,000000 \\
4\end{array}$ & 0,0000050 & 0,0000008 & 0,0000006 & 0,0000001 & 0,0000029 & 0,0000006 & 0,0000003 & 0,0000178 & 0,0000068 \\
\hline LOQ & 0,0000014 & 0,0000165 & 0,0000027 & 0,0000021 & 0,0000003 & 0,0000096 & 0,0000020 & 0,0000010 & 0,0000594 & 0,0000228 \\
\hline
\end{tabular}

\subsection{Kuyu Suyu Örneklerinin Kemometrik Analiz Sonuçları}

Kemometrik analizlerde ham veri büyük öneme sahiptir. Yapılan bir deneysel çalışma sonrasında elde edilen verilerin kemometrik hesaplamalarına geçmeden önce verilerin özellikleri dikkatle incelenmelidir. Elde edilen veriler arasında birbirinden çok farklı değerler bulunuyorsa ya da değerler arası büyük dengesizlik varsa, verilerin benzer birimlere çevrilmeleri veya ortalama 
değer etrafında toplanması gerekebilir. Bunun gibi durumlarda verilere merkezileştirme, standartlaştırma ve normalizasyon gibi verilerin analize hazırlanmasına yönelik işlemler uygulanır (Brereton, 2007).

\subsubsection{Temel Bileşen Analizi (PCA)}

Hatay'ın farklı bölgelerinden toplanan 35 kuyu suyu numunesinin $\mathrm{Mn}, \mathrm{Ni}, \mathrm{Co}, \mathrm{Al}, \mathrm{Cd}, \mathrm{Cr}, \mathrm{Cu}$, $\mathrm{Fe}, \mathrm{Pb}$ ve $\mathrm{Zn}$ verilerine Excel programı kullanılarak temel bileşen analizi uygulanmıştır. Böylece su örneklerini karakterize eden scores ve su örneklerindeki ağır metalleri karakterize eden loadings değerleri elde edilmiştir. Ayrıca su örnekleri arasındaki grupları karakterize eden eigen değerler hesaplanarak grafiğe geçirilmiştir. Eigen değerler ve her bir temel bileşenin yüzde varyans değerleri Tablo 3.4. de verilmiştir.

Tablo 3.4. Su örneklerinin eigen değerleri ve her bir temel bileşenin yüzde varyans değerleri

\begin{tabular}{cccc}
\hline $\begin{array}{c}\text { Temel bileşen } \\
\text { Sayısı }\end{array}$ & Eigen değer & Varyans (\%) & Toplam varyans (\%) \\
\hline $\mathbf{1}$ & 116,250 & 34,191 & 34,191 \\
$\mathbf{2}$ & 57,990 & 17,056 & 51,247 \\
$\mathbf{3}$ & 50,013 & 14,710 & 65,957 \\
$\mathbf{4}$ & 34,087 & 10,026 & 75,983 \\
$\mathbf{5}$ & 28,383 & 8,348 & 84,330 \\
$\mathbf{6}$ & 16,947 & 4,984 & 89,315 \\
$\mathbf{7}$ & 13,794 & 4,057 & 93,372 \\
$\mathbf{8}$ & 11,580 & 3,406 & 96,778 \\
$\mathbf{9}$ & 6,032 & 1,774 & 98,552 \\
$\mathbf{1 0}$ & 4,924 & 1,448 & 100,000 \\
\hline
\end{tabular}

Tablo 3.4. incelendiğinde ilk dört temel bileşenin toplam varyansın \% 75.983' ünü açıkladığı görülmektedir. İlk temel bileşenin değeri \% 34.191 ve diğer temel bileşenler sırasıyla \% 17.056, \% 14.710 ve \% 10.026 şeklindedir. Tablo 3.5. de toplam verinin \% 75.983 'ünü açıklayan ilk dört temel bileşenin loading değerleri görülmektedir. 
Tablo 3.5. Altı temel bileşen için değişkenlerin loading değerleri

\begin{tabular}{ccccc}
\hline Değişken & PC1 & PC2 & PC3 & PC4 \\
\hline $\mathbf{M n}$ & 0,1205 & 0,2529 & 0,4372 & 0,6712 \\
$\mathbf{N i}$ & $-0,3958$ & $-0,1612$ & 0,3558 & $-0,0217$ \\
$\mathbf{C o}$ & $-0,4498$ & $-0,0383$ & 0,0533 & 0,1796 \\
$\mathbf{A l}$ & $-0,3853$ & 0,0944 & 0,1300 & 0,1267 \\
$\mathbf{C d}$ & $-0,2492$ & 0,1739 & $-0,4127$ & 0,5216 \\
$\mathbf{C r}$ & 0,1729 & $-0,5681$ & $-0,2929$ & 0,2140 \\
$\mathbf{C u}$ & $-0,4575$ & 0,0093 & 0,0658 & $-0,1833$ \\
$\mathbf{F e}$ & $-0,0674$ & $-0,5515$ & 0,4632 & $-0,0429$ \\
$\mathbf{P b}$ & $-0,3996$ & 0,0541 & $-0,3619$ & $-0,2069$ \\
$\mathbf{Z n}$ & $-0,1124$ & $-0,4894$ & $-0,2377$ & 0,3233 \\
\hline
\end{tabular}

PC1 ile PC2 verileri arasında çizilen scores ve loading noktaları Şekil 3.1.de verilmiştir. Şekil 3.1. (a) incelendiğinde kuyu suyu örneklerinin A, B ve C olarak adlandırılan üç farklı grup oluşturduğu görülmektedir. Genel olarak bir değerlendirme yapıldığında A grubu örneklerinin Antakya-Merkez bölgesinden toplanan numuneleri içerdiği görülmektedir. Antakya-Serinyol ve Antakya-Merkez bölgelerinden alınan 7 ve 30 numaralı kuyu suyu numuneleri içerdikleri $\mathrm{Mn}, \mathrm{Ni}, \mathrm{Co}, \mathrm{Al}, \mathrm{Cd}, \mathrm{Cr}, \mathrm{Cu}$, $\mathrm{Fe}, \mathrm{Pb}$ ve $\mathrm{Zn}$ içeriklerindeki benzerlik nedeniyle $\mathrm{B}$ grubunu oluşturmaktadır. $\mathrm{C}$ grubu içerdiği kuyu suyu numunesi sayısı bakımından en kalabalık grup olmuştur. Bu grubun içerisinde Antakya-Merkez, Antakya-Serinyol, Antakya-Karaali Beldesi ve Hatay-İskenderun bölgelerinden alınan kuyu suyu numuneleri bulunmaktadır. Şekil 4.1.'den görüldüğü gibi A grubunun tamamı PC1 ve PC2' nin pozitif değerleri tarafından karakterize edilmektedir. B gurubunda ise grubu oluşturan iki numunede negatif bölgede bulunmaktadır. C grubu incelendiğinde ise grubun bir yarısının PC1 ve PC2' nin negatif değerleri diğer yarısının ise PC1 ve PC2' nin pozitif değerleri tarafından karakterize edildiği görülmektedir. Şekil 3.1. (b) A,B ve C gruplarını hangi elementlerin karakterize ettiğini göstermektedir. Buna göre A grubu kuyu sularını $\mathrm{Cu}, \mathrm{Pb}, \mathrm{Al}$ ve $\mathrm{Cd}$ elementleri; B grubu kuyu sularını $\mathrm{Zn}, \mathrm{Fe}$ ve $\mathrm{Cr}$ elementleri; $\mathrm{C}$ grubu kuyu sularını ise $\mathrm{Mn}, \mathrm{Cd}, \mathrm{Pb}, \mathrm{Al}$, Ni ve $\mathrm{Zn}$ elementleri karakterize etmektedir. 


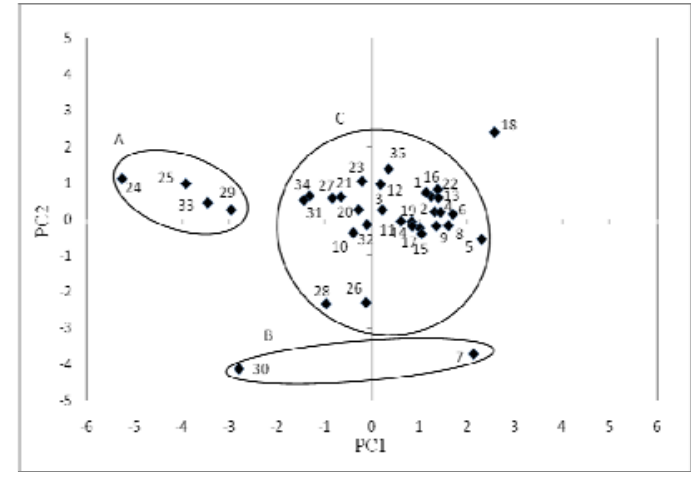

(a)

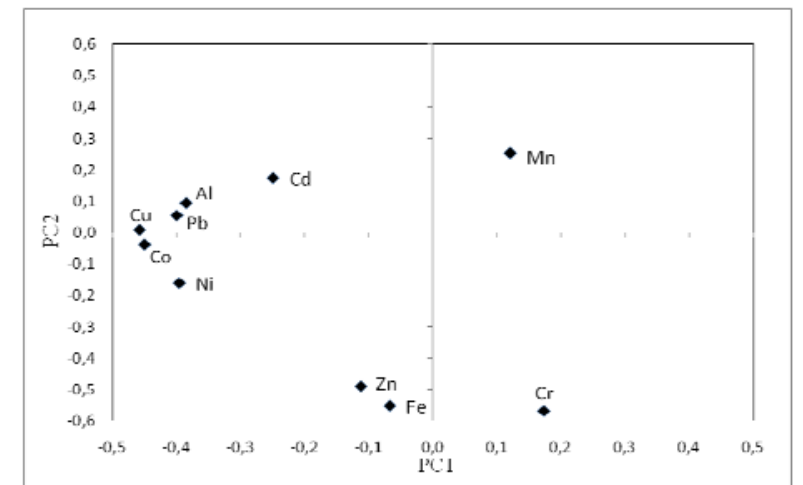

(b)

Şekil 3.1 Temel bileşen analizi sonuçları (a) 1. ve 2. Temel bileşenlerin scores değerleri (b) 1. ve 2. Temel bileşenlerin loadings değerleri

\subsection{2. Öbekleme Analizi (CA)}

Kuyu suyu örneklerinin ICP-OES metodu kullanılarak analiz edilmesiyle elde edilen ağır metal düzeylerine ait verilere hiyerarşik toplam ilişsilendirme öbekleme analiz yöntemi uygulanmıştır (Brereton, 2003). Öbekleme analizi farklı bölgelerden alınarak analiz edilen su örneklerinin kimyasal bileşimine göre benzerliklerini ortaya koymakta kullanılmıştır. Elde edilen öbekleme analiz sonuçlarının temel bileşen analiz sonuçları ile tamamen örtüştüğü belirlenmiştir. Şekil 3.2. (a) incelendiğinde \% 80 benzerlik seviyesinde kuyu suyu örneklerinin üç ana gruba ayrıldığı görülebilir. Soldan sağa doğru sırasıyla ilk grup Antakya-Merkez numunelerinden, ikinci grup Antakya-Serinyol ve Antakya-Merkez numunelerinden, üçüncü grup ise Antakya-Merkez, Antakya-Serinyol, AntakyaKaraali Beldesi ve Hatay-İskenderun bölgelerinden alınan kuyu suyu numunelerinden oluşmuştur. Bu gruplar kuyu suyu örneklerinin ağır metal içeriğine bağlı olarak incelendiğinde Şekil 3.2. (b)' de görüldüğü gibi ilk grup $\mathrm{Pb}, \mathrm{Cd}, \mathrm{Al}, \mathrm{Cu}, \mathrm{Co}$ ve $\mathrm{Ni}$; ikinci grup $\mathrm{Fe}, \mathrm{Zn}$ ve $\mathrm{Cr}$; üçüncü grup ise $\mathrm{Mn}, \mathrm{Cr}$, $\mathrm{Zn}, \mathrm{Fe}, \mathrm{Ni}, \mathrm{Co}, \mathrm{Cu}$ ve Al elementlerinden meydana gelmiştir. Sonuçlardan değişkenler (element içerikleri) ile öbeklenmiş kuyu suyu örnekleri arasında korelasyon olduğu görülmektedir. 


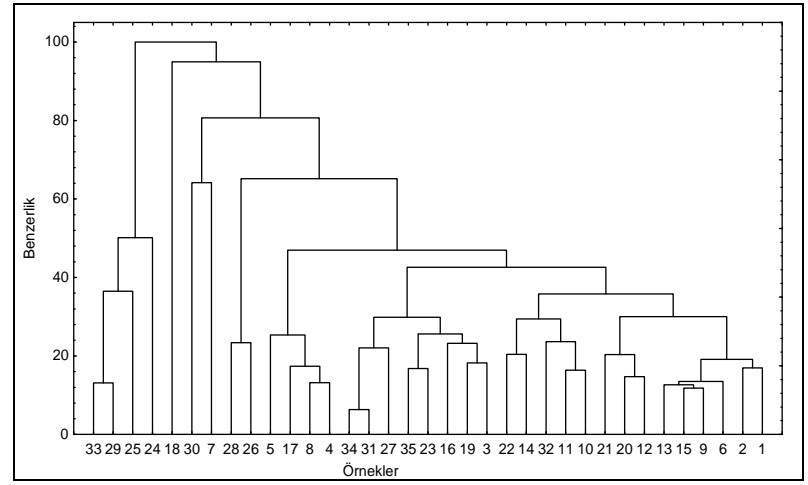

(a)

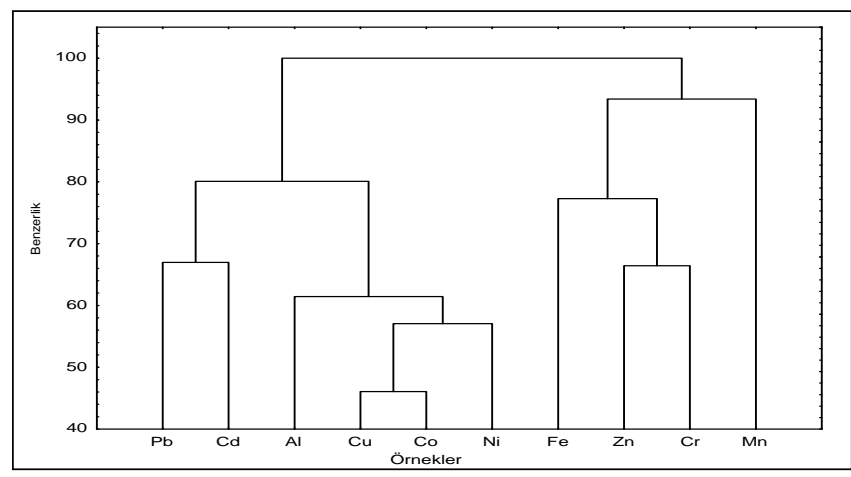

(b)

Şekil 3.1. Kuyu suyu örneklerinde öbekleme analizi sonucunda oluşan dendogramlar (a) Kuyu suyu numuneleri (b) Elementler

\subsubsection{Korelasyon Analizi}

Kuyu suyu örneklerinin ICP-OES metodu kullanılarak analiz edilmesiyle elde edilen ağır metal düzeylerine ait verilere korelasyon analizi uygulanmıştır. Elde edilen sonuçlar Çizelge 3.6. da verilmiştir. $\mathrm{Bu}$ sonuçlara göre korelasyon katsayısı 0,5 ' ten büyük elementler arasında korelasyon bulunmaktadır. Çizelge 3.6. incelendiğinde $\mathrm{Ni}, \mathrm{Co}$ ve $\mathrm{Cu}$; $\mathrm{Co}, \mathrm{Cu}$ ve $\mathrm{Pb} ; \mathrm{Cu}$ ve $\mathrm{Pb}$ elementleri arasında iyi korelasyon olduğu görülmektedir. 1. ve 2. temel bileşenlerin loadings değerlerini içeren Şekil 3.1. (b) incelendiğinde şekildeki elementlerin konumları ile aralarında korelasyon gözlenen elementlerin örtüştüğü görülmektedir.

Tablo 3.6. Su örneklerinin ağır metal içeriklerine ait korelasyon katsayıları

\begin{tabular}{|c|c|c|c|c|c|c|c|c|c|c|}
\hline & Mn & $\mathbf{N i}$ & Co & Al & Cd & $\mathrm{Cr}$ & $\mathbf{C u}$ & $\mathbf{F e}$ & $\mathbf{P b}$ & $\mathbf{Z n}$ \\
\hline Mn & 1 & & & & & & & & & \\
\hline $\mathbf{N i}$ & $-0,029$ & 1 & & & & & & & & \\
\hline Co & $-0,049$ & 0,543 & 1 & & & & & & & \\
\hline Al & $-0,015$ & 0,479 & 0,484 & 1 & & & & & & \\
\hline Cd & $-0,063$ & 0,101 & 0,400 & 0,360 & 1 & & & & & \\
\hline $\mathrm{Cr}$ & $-0,223$ & $-0,268$ & $-0,169$ & $-0,219$ & $-0,019$ & 1 & & & & \\
\hline $\mathrm{Cu}$ & $-0,217$ & 0,561 & 0,702 & 0,471 & 0,201 & $-0,383$ & 1 & & & \\
\hline $\mathrm{Fe}$ & $-0,057$ & 0,419 & 0,171 & 0,150 & $-0,281$ & 0,311 & 0,090 & 1 & & \\
\hline $\mathbf{P b}$ & $-0,402$ & 0,367 & $\mathbf{0 , 5 0 3}$ & 0,444 & 0,371 & $-0,157$ & 0,542 & $-0,201$ & 1 & \\
\hline $\mathbf{Z n}$ & $-0,102$ & 0,193 & 0,158 & $-0,069$ & 0,105 & 0,381 & 0,200 & 0,162 & 0,190 & 1 \\
\hline
\end{tabular}

Analiz yapılan tüm kuyu sularında pH değerleri 6,40-8,61 arasıdır. Buna göre içme sularında tespit ettiğimiz pH değerlerinin TS 266 ve WHO’ya uygun olduğu görülmüştür. Sert sular köpük 
oluşturmak için çok sabun kullanımını gerektiren sular olarak tanımlanırlar (Samsunlu, 2008). Yumuşak suların tadının ve içiminin iyi olmasına karşın, sert suların tadı iyi değildir. Ancak sert suların sindirimi yumuşak sulara kıyasla daha güçtür (Yumuturuğ ve ark. 1980). TS 266 sertlik limitlerini $\mathrm{CaCO}_{3}$ cinsinden $50 \mathrm{mg} / \mathrm{L}$ olarak vermiştir. WHO içme suyu standartları da aynıdır. Analiz yapılan tüm kuyu sularındaki değerler 156,0-428,0 $\mathrm{mg} \mathrm{CaCO}_{3} / \mathrm{L}$ aralığında değişmektedir. Buradan yola çıkılarak Hatay merkezdeki kuyu sularının sert ve kireçli olduğunu söylemek mümkündür. Kalsiyum ve magnezyum sertliğine bakıldığında; kalsiyum için TS 266 da tavsiye edilen değer $75 \mathrm{mg} / \mathrm{L}$ iken izin verilen maksimum değer $200 \mathrm{mg} / \mathrm{L}$ 'dir. Magnezyum için bu değerler 50-150 mg/L'dir. Analiz yapılan Hatay merkezdeki kuyu sularının kalsiyum değerleri 4,00-313,00 $\mathrm{mg} / \mathrm{L}$ aralığında değişmekte olup birçok numune için TS 266 içme suyu standartlarında tavsiye edilen değerin altında olduğu gözlemlenmiştir. Analiz yapılan Hatay merkezdeki kuyu sularının magnezyum değerleri 115,00-321,00 mg/L aralığında değişmekte olduğu gözlemlenmiştir. Buna dayanarak Hatay merkezdeki yeraltı sularının sert olmasında magnezyum tuzlarının etkisinin büyük olduğunu söylemek mümkündür.

Hatay'ın farklı bölgelerinden toplanan kuyu suyu numunelerinin temel bileşen analizleri sonucunda su örneklerini karakterize eden scores ve su örneklerindeki ağır metalleri karakterize eden loadings değerleri elde edilmiştir. Ayrıca su örnekleri arasındaki grupları karakterize eden eigen değerler hesaplanarak grafiğe geçirilmiştir. Elde edilen sonuçlarda ilk dört temel bileşenin toplam varyansın \% 75.983' ünü açıkladığı görülmüştür. PC1 ile PC2 verileri arasında çizilen scores ve loading grafiklerine göre kuyu suyu örneklerinin A, B ve C olarak adlandırılan üç farklı grup oluşturduğu görülmüştür. Genel olarak bir değerlendirme yapıldığında A grubu örneklerinin AntakyaMerkez bölgesinden toplanan numuneleri içerdiği belirlenmiştir. Antakya-Serinyol ve Antakya Merkez bölgelerinden alınan 7 ve 30 numaralı kuyu suyu numuneleri içerdikleri $\mathrm{Mn}, \mathrm{Ni}, \mathrm{Co}, \mathrm{Al}, \mathrm{Cd}, \mathrm{Cr}, \mathrm{Cu}$, $\mathrm{Fe}, \mathrm{Pb}$ ve $\mathrm{Zn}$ içeriklerindeki benzerlik nedeniyle $\mathrm{B}$ grubunu oluşturmuştur. $\mathrm{C}$ grubu içerdiği kuyu suyu numunesi sayısı bakımından en kalabalık grup olmuştur. Bu grubun içerisinde Antakya-Merkez, Antakya-Serinyol, Antakya-Karaali Beldesi ve Hatay-İskenderun bölgelerinden alınan kuyu suyu numuneleri yer almıştır. A, B ve C gruplarını hangi elementlerin karakterize ettiğinin belirlenmesine yönelik yapılan çalışmada A grubu kuyu sularını $\mathrm{Cu}, \mathrm{Pb}$, $\mathrm{Al}$ ve Cd elementleri; B grubu kuyu sularını $\mathrm{Zn}$, Fe ve $\mathrm{Cr}$ elementleri; $\mathrm{C}$ grubu kuyu sularını ise $\mathrm{Mn}, \mathrm{Cd}, \mathrm{Pb}, \mathrm{Al}$, $\mathrm{Ni}$ ve $\mathrm{Zn}$ elementlerinin karakterize ettiği görülmüştür.

Öbekleme analiz sonuçları incelendiğinde verilerin temel bileşen analiz sonuçları ile tamamen örtüştüğü belirlenmiştir. \% 80 benzerlik seviyesinde kuyu suyu örneklerinin üç ana gruba ayrıldığı görülmüştür. Soldan sağa doğru sırasıyla ilk grup Antakya-Merkez numunelerinden, ikinci grup Antakya-Serinyol ve Antakya-Merkez numunelerinden, üçüncü grup ise Antakya-Merkez, AntakyaSerinyol, Antakya-Karaali Beldesi ve Hatay-İskenderun bölgelerinden alınan kuyu suyu 
numunelerinden oluşmuştur. Bu gruplar kuyu suyu örneklerinin ağır metal içeriğine bağlı olarak incelendiğinde ilk grup $\mathrm{Pb}, \mathrm{Cd}, \mathrm{Al}, \mathrm{Cu}$, Co ve $\mathrm{Ni}$; ikinci grup $\mathrm{Fe}, \mathrm{Zn}$ ve $\mathrm{Cr}$; üçüncü grup ise $\mathrm{Mn}, \mathrm{Cr}$, $\mathrm{Zn}, \mathrm{Fe}, \mathrm{Ni}, \mathrm{Co}, \mathrm{Cu}$ ve Al elementlerinden meydana gelmiştir. Sonuçlardan değişskenler (element içerikleri) ile öbeklenmiş kuyu suyu örnekleri arasında korelasyon olduğu görülmüştür.

Hatay'ın farklı bölgelerinden toplanan kuyu suyu numunelerinin korelasyon analizi sonucunda $\mathrm{Ni}, \mathrm{Co}$ ve $\mathrm{Cu}$; $\mathrm{Co}, \mathrm{Cu}$ ve $\mathrm{Pb} ; \mathrm{Cu}$ ve $\mathrm{Pb}$ elementleri arasında iyi korelasyon olduğu görülmüştür. 1. ve 2. temel bileşenlerin loadings değerlerini içeren grafik incelendiğinde şekildeki elementlerin konumları ile aralarında korelasyon gözlenen elementlerin örtüştüğü görülmüştür. Sonuç olarak Hatay’ın farklı bölgelerinden toplanan 35 farklı kuyu suyu örneği kalite parametrelerine göre kemometrik teknikler kullanılarak karakterize edilmiş ve temel bileşen analizi, öbekleme analizi ve korelasyon analizinin farklı orijinlere sahip kuyu sularının içermiş oldukları ağır metal içeriklerine göre ayrılmasında yararlı metotlar olduğu saptanmıştır.

\section{Teşekkür}

Bu çalışma, Hatay Mustafa Kemal Üniversitesi Bilimsel Araştırma Projeleri koordinasyon Birimi tarafından desteklenmiştir.

\section{Kaynaklar}

Fetter, G. W. (1994). Applied Hydrogeology. New Jersey: Prentice Hall

Bear, J., Cheng, A.H.D., (1999). Chap. 1, In Seawater Intrusion in Coastal Aquifers-Concepts , Methods, and Practices.

Tombul, M. ve Bilgin, M., (1998). Eskişehir Yeraltı Sularının Kirlenme Sebepleri ve Kirlenme Düzeyi. In: Kayseri 1. Atıksu Sempozyumu1, 22-24 Haziran, Kayseri,Turkey,.

Burak, S., Duranyıldız, İ. ve Yetiş, Ü. (1997). Ulusal Çevre Eylem Planı: Su Kaynaklarının Yönetimi. Devlet Su İşleri Genel Müdürlügüu, Ankara.

Brereton, R.G., (2003). Chemometrics Data Analysis for the Laboratory and Chemical Plant, John Wiley \& Sons, Ltd.

Brereton, R. G., (2007). Applied Chemometrics for Scientists, Wiley (45) 331-336.

Samsunlu, A., (2008). Çevre Mühendisliği Kimyası, Birsen Yayınevi, 214-215.

Yumurutuğ S, Sungur T., (1980). Hijyen, Koruyucu Hekimlik. Ankara Üniversitesi Tıp Fakültesi Yayını No:393 